\title{
They Might as Well Be Speaking Chinese: The Changing Chinese Linguistic Situation in Suriname under New Migration
}

\author{
Paul B. Tjon Sie Fat
}

Introduction

This chapter presents one of the most obvious local examples, to the Surinamese public at least, of the link between mobility, language, and identity: current Chinese migration. These 'New Chinese' migrants since the $1990 \mathrm{~s}$ were linguistically quite different from the established Hakkas in Suriname, and were the cause of an upsurge in anti-Chinese sentiments. It will be argued that the aforementioned link is constructed in the Surinamese imagination in the context of ethnic and civic discourse to reproduce the image of a monolithic, undifferentiated, Chinese migrant group, despite increasing variety and change within the Chinese segment of Surinamese society. The point will also be made that the Chinese stereotype affects the way demographic and linguistic data relating to Chinese are produced by government institutions. We will present a historic overview of the Chinese presence in Suriname, a brief ethnographic description of Chinese migrant cohorts, followed by some data on written Chinese in Suriname. Finally we present the available data on Chinese ethnicity and language from the Surinamese General Bureau of Statistics (ABS).

An ethnic Chinese segment has existed in Surinamese society since the middle of the nineteenth century, as a consequence of Dutch colonial policy to import Asian indentured labour as a substitute for African slave labour. Indentured labourers from Hakka villages in the Fuitungon Region (particularly Dongguan and Baoan $)^{1}$ in the second half of the nineteenth century made way for entrepreneurial chain migrants up to the first half of the twentieth

1 The established Hakka migrants in Suriname refer to the area as fui ${ }^{5} t_{u n g}{ }^{I} n^{I}$ (惠東安), which is an anagram of the Kejia pronunciation of the names of the three counties where the 'Old Chinese' migrant cohorts in Suriname come from: fui ${ }^{5}$ jong $^{2}$ (惠陽 Putonghua: huiyáng), tung $^{1}$ Kon $^{1}$ (東莞 Ртн: dōngguăn), and pau $^{3}$ on $^{1}$ (寶安 Ртн: băoān). For the informants in Suriname the term referred to the nineteenth century districts of Dongguan, Huiyang and Xin'an in the Hong Kong periphery, currently corresponding to areas in Dongguan

(C) PAUL B. TJON SIE FAT, 2015 | DOI 10.1163/9789004280120_010

This is an open access chapter distributed under the terms of the Creative Commons Attribution-

Noncommercial 3.0 Unported (CC-BY-NC 3.0) License. 
century, who developed an ethnic ownership economy based on retail trade and their own adaptive institutions. Using T'sou's definition of a 'Chinese language community', a thriving Chinese-speaking group was in existence in Suriname by the early twentieth century; there were Chinese cemeteries (implying that Chinese script was used on gravestones and Chinese was spoken during funeral ceremonies), commercial and socio-cultural associations, Chinese religious institutions, Chinese-language education (written Chinese, taught in Kejia), Chinese-language media, and at least two consecutive generations with a basic knowledge of the ancestral dialect (T'sou 1987: B-16a). ${ }^{2}$ Assimilation produced a generational cleavage within the community between those born in China (Tong'ap) and those born in Suriname or of mixed heritage (Laiap)..$^{3}$ In the 196os acculturated Fuitungon Hakka chain migrants came via Hong Kong, while the latest migrant cohorts arrived since the 199os after the People's Republic of China (PRC) instituted economic reforms and eased restrictions on emigration.

By the start of the 1990s Chinese migration to Suriname sharply increased, and the impact of the 'New Chinese' in a society where ethnic Chinese had

Municipality, Huiyang County, Baoan County, Shenzhen Special Economic Zone, and the New Territories in the Hong Kong Special Administrative Region.

Note on transcriptions: For convenience in reading, Hanyu pinyin without tonal marking is used for names. Full pinyin is used wherever the sound of Putonghua matters, or where the language plays a role. Similarly, Kejia names are transcribed according to the Fuitungon Kejia pronunciation dictionary (Chin-a-Woeng 2008).

2 This chapter is about the Sinitic languages in Suriname, and so the non-Han component of Chinese migration to Suriname will not be considered. In any case, the Chinese Koreans are the only substantial group of 'ethnic minority overseas Chinese' (少數民族華僑華人, a political term used in the People's Republic of China to gain some measure of State control over the transnational links of non-Han migrants from the PRC and their foreign coethnics) in Suriname. Ethnic Koreans are one of the 56 Minority Nationalities recognised by the PRC, and the majority live in Yanbian Korean Autonomous Prefecture in Jilin Province, situated within the territories of the early medieval kingdoms of Goguryeo and Barhae. Originally forestry workers, they link up with the South Korean fishermen in Suriname and the South Korean migration network in South America (especially to the Southern Cone region). But as PRC citizens who are fully competent in Chinese spoken and written language, to Surinamese they are generally indistinguishable from other Northeastern Chinese migrants.

3 The word Laiap (lai ${ }^{2} a p^{7}$ 泥鴨/坭鴨, lit.: 'Mud Duck') derives from the Kejia name of an old duck breed in Guangdong Province, the offspring of a male $\operatorname{fan}^{1} a p^{7}$ (番鴨, lit.: 'foreign duck and a female of a local pond duck breed referred to as $\operatorname{tong}^{2} a p^{7}$ (唐鴨, lit.: 'Chinese duck', i.e. local duck breed). Early on, the local-born children of Chinese migrants were often born of Creole mothers; local-born eventually became synonymous with mixed ancestry. Laiap is considered something of a racist slur by Kejia-speakers. 
been gradually assimilating, triggered an upsurge in anti-Chinese sentiments. As an aspect of new globalised migration, New Migrants from China are literally found all over the globe. Compared to earlier Chinese migrants, the New Migrants typically have new types of transnational ties with the PRC as their homeland, through modern mass media and mass transit. The New Chinese in Suriname hail from every imaginable region in the Chinese world, but the vast majority arrived from the coastal provinces of the PRC, from Hainan in the south all the way to Liaoning in Manchuria. The majority in Suriname are from southern Zhejiang Province.

Whether globalisation of the PRC economy drives migration to destinations like Suriname or whether it is New Migrants from China who are introducing PRC products to new markets, New Chinese socio-economic positioning had a clear impact on the image of Chinese in Suriname. Their often large supermarkets came to represent the most concrete sign and outcome of New Chinese migration and of the growing influence and power of the PRC in the region. The Surinamese public tends to misunderstand the PRC's presence in Suriname in terms of globalisation and geopolitics and conflates the PRC, Chinese migrants survival strategies and ethnic Chinese as 'China'/'Chinese'. As a consequence Chinese migrants and ethnic Chinese in Suriname need to choose their positioning strategies with the general image of monolithic Chineseness, in which 'China' and 'Chinese' are inextricably intertwined.

Since the arrival of the New Chinese, the linguistic and cultural landscape within the Chinese segment of Suriname has become more complex. Up to then 'Chinese' and Fuitungon Hakka culture and language were virtually synonymous in Suriname, as in other locations in the Caribbean such as Jamaica and Trinidad and Tobago. In Suriname, these 'Old Chinese' had to contend with at least five languages: the dialect of their ancestral villages, Sranantongo, Dutch, Mandarin (initially Guoyu, later Putonghua (РTH)), ${ }^{4}$ and English. The New Chinese added their own local languages to the mix, and their transnational orientation increased the importance of PTH and English (being world languages). However, most Surinamese were ignorant of any fundamental change, such as the shift of the main symbol of self-identifying Chinese ethnic identity - Chinese language - from Fuitungon Kejia to PTH, the official language of the People's Republic of China. Why does Suriname seem blind-or

4 'Mandarin' is an English rendition of the Portuguese translation of Chinese guānhuà (官話): "the language of the officials." That language was a koine, a melding of various Chinese varieties, dominated by Northern Chinese dialects. This koine led to the twentieth century standards of Guoyu and Putonghua, which are less koines but lingua francas more clearly related to Northern Chinese (South Coblin 2000). 
rather deaf - to the changing Chinese linguistic ecology, and what exactly is it that is people are not seeing and hearing?

First we will look at language and identity among the Hakka of Suriname, the 'Old Chinese', and then familiarise ourselves with the New Chinese migrants and the languages they brought. To complete the picture of what Chinese language in Suriname entails we will also explore written Chinese. By critically observing the way Chinese ethnicity and language are handled in census and demographic statistics, we hope to understand how the Surinamese State deals with changes in the multicultural—and ethnopolitical—landscape. Finally, we will consider the link between Chinese language and instrumental ethnic identity.

Up to the arrival of New Migrants in the early 1990s, Chinese language and culture meant the language and culture of migrants from the Fuitungon region in the Pearl River Delta, people who have tended to self-identify and have been identified as Hakka. During the 196os a form of Hakka nationalism developed among certain ethnic Chinese intellectuals in Suriname, in response to earlier cultural and political policies of the Republic of China, the memory of nineteenth century Hakka-Punti conflicts in the migrant homelands in Southern China, the low esteem that Hakka culture and language had in the eyes of more recent migrant cohorts (the 'Hong Kong Chinese'), and the drive to acquire recognition of the Chinese of Suriname as authentic Surinamese citizens. In their politics of identity the close link between Chineseness and Hakka identity was paramount, and the general awareness of the existence of Hakka in Suriname is due to their influence.

'Hakka' is used here loosely to refer to group identity, while following current practice in Chinese linguistics the 'Hakka dialect' is called 'Kejia', in order to distinguish between politics of identity and recognition and the rise and fall of this linguistic variety in Suriname. One should also recognise that Hakka ethnic identity is a social construct with a surprisingly recent history, and that Kejia as a linguistic category is less clear-cut than would seem to be the case.

2.1

Hakka

The term 'Hakka' (客家) basically means 'outsider', and originated in nineteenth century Guangdong Province when local Cantonese speakers (labelled pun $^{3} t^{\prime} i^{3}$ in Kejia: 'of this place', i.e. the established) were confronted with migrants from outside the province ( $h a a k^{3} \mathrm{ga}^{1}$, Cantonese: 'guest households', 
i.e. outsiders). The notion of Hakka as an ethnic identity linked to their dialect, Kejia, arose during this time (Cohen 1995). The element 客 (kè in PTH) is actually fairly common in local Chinese expressions which refer to 'Chinese not from around here' (Prager Banner 2000: 43). The origins of the people currently labelled Hakka can be traced to migrations from the sixteenth to the nineteenth centuries of poor households in Southern China, towards peripheries of economic centres in river drainage basins, enabled by the introduction of New World crops. ${ }^{5}$ Hakka identification was thus fundamentally contrastive, in the sense of day-to-day competition between the established and outsiders (one possible translation of the term 'Hakka'). Hakkas are the exception to the Chinese rule of defining varieties of Han-Chinese culture and language as fundamentally regional. Even so, Hakka identity is strongly linked to areas in Guangdong province where Kejia varieties dominate, such as Meizhou.

Kejia varieties and Hakka identity are easily conflated (i.e. Kejia dialects are the languages spoken by people who identify or are identified as Hakka and Hakka are people who speak Kejia), often without sufficient linguistic arguments. Modern Hakka identity discourse can be traced to the politics of recognition conducted by Hakka intellectuals in the early twentieth century, basically in the aftermath of the nineteenth century conflicts. One of these intellectuals, Luo Xianglin, is most often quoted as an authority on the roots of Hakka identity (Lozada 1998: 93). He declared that the Hakka are Han, that they came from the north, that Hakka have unique cultural markers, and that Kejia is particularly close to medieval Northern Chinese language (Luo 1933). Read as a credo his book stresses that Hakka roots are primordial and respectable, meaning that they do not extend to non-Han groups such as Miao, Yao, Zhuang, and She, and are older than the Guangdongese conflicts.

It is safe to say that the idea of a Hakka group is currently taken for granted by most people, despite the fact that it is virtually impossible to frame Hakka ethnicity in unambiguous terms. There is no easily accessed Hakka identity (on the one hand ambiguity through cultural and linguistic shifts, assimilation and contingent identification makes easy definitions of Hakka-ness impossible, on the other hand no uncontested universal Hakka identity exists). When it does surface one should not be surprised if it is instrumental. In Suriname, Hakka identity currently does not produce any ethnic or cultural capital beyond the realm of Chinatown politics and Chinese business networks, and

5 For the link between Hakka migrants and pengmin (棚民 'shack people') labour migrants, see Leong 1997. Charles Mann (2011: 180-187) presents a very readable explanation of the role of maize and sweet potatoes in the spread of Hakkas in in the hills of Guangdong Province based on current Western and Chinese sources. 
power dynamics among the elites of various Chinese regional backgrounds. With regard to broader Surinamese society Hakka ethnic identity is virtually meaningless. Anthropological and linguistic field workers risk taking 'Hakka' as a ontological category instead of a social construct that links a vague ethnic identity with an almost equally vague linguistic category, and thus risk missing continuous processes of assimilation and language shift that are characteristic of Chinese groups overseas.

\subsection{Kejia}

Kejia is a Chinese dialect group, one of up to 11 that have been identified, namely: Northern Chinese (Mandarin), Jin, Hui, Xiang, Gan, Wu, Min, Kejia, Yue, Pinghua (Chappell 2001: 6). The essentialist bias in the various discourses of Chinese identity is projected onto the issue of Hakka language, and so Hakka identity requires a single language, but in fact there is no unambiguous characterisation that can take account of all known Kejia varieties (Sagart 1998, Prager Banner 2000). Kejia varieties can be placed on continuums between Kejia, Min and Yue (Lau 2003). PRC linguists conventionally name the Kejia variety of Meizhou Muncipality in Guangdong province as a standard representative of the Kejia dialect group, mainly because Kejia has long been the dominant language in the Meizhou (ancient Jiayingzhou) region. This qualification combines with the high status accorded to speakers of Meizhou Kejia by other Kejia-speakers to produce the image of Meizhou Kejia as 'real Kejia', 'pure Kejia', even the only Kejia dialect.

The Kejia varieties of the Fuitungon Hakka migrant cohorts in Suriname, Fuitungon Kejia, ${ }^{6}$ come from the hilly areas where Dongguan, the Shenzhen SEz/Baoan, and Huiyang meet (Li 1997: 3). These varieties are mutually intelligible; the lexicon of Huiyang Kejia has evidently been more influenced by Cantonese (Zhang 1999), and linguistic data from local publications indicate that tones are an important difference (Baoan Difang Zhi; Dongguan Difang Zhi; Zhang 1999, Xie and Huang 2007). Fuitungon Hakkas in Suriname usually describe the different varieties as 'accents'. Not surprisingly, a local Kejia variety has developed in Suriname, with features such as reduced tones, archaic vocabulary items, Sranantongo loanwords, and often showing code-alternation practices involving Dutch and Sranantongo (Tjon Sie Fat 2002). ${ }^{7}$ Kejia had been the only form of spoken Chinese in Suriname for a long time, and its low status had been irrelevant until the introduction of Cantonese as a public medium in the 1970 s.

6 Fuitungon Kejia: Sinitic $>$ Kejia $>$ Yuetai $>$ Xinhui.

7 Also called 'Laiap Hakka'. 
What is clear is that during the last decade or so Kejia has lost its place as essential Chinese lingua franca to РTH - which lowered the already low status of Kejia even further. The newcomers refuse to learn Kejia, and Hakkas who do not learn PTH are considered 'incomplete'; the inability to speak PTH is a symptom of Chinese who are out of touch with modern China. PTH thus also exposes a generation gap among the Tong'ap. The latest Fuitungon Hakka immigrants have learned PTH in school, and are thus able to communicate with non-Hakka immigrants. While newcomers recognise the usefulness of Sranantongo as inter-ethnic lingua franca in Suriname, they are ambiguous about Dutch, explaining that the role of English in the world is rather like that of РTH in China, and that learning Dutch is not worth the investment of time and money-like learning Kejia. Dutch is the dominant local language, rather like Cantonese in Guangdong Province, a view bolstered by the relatedness of Dutch and English. But unlike Cantonese, Dutch in Suriname functions as a guānhuà (官話), an official language, a language one needs at all formal levels of society. In PTH and Kejia Sranantongo is called a tǔhuà $/ t^{\prime} u^{3} w a^{3}$ (土話 lit.: 'earth speech', local patois) —in many ways rather like Fuitungon Kejia. ${ }^{8}$

Fuitungon Hakkas' resentment about the inferior status of Kejia in Suriname is very rarely voiced. In 2004 the newspaper of the Chung Fa Foei Kon sociocultural organisation printed a short text titled 'Kejia Is Quietly Going Extinct'. The writer, a Fuitungon Hakka whose name read Luo Quan in PTH, complained about the continued disrespect of the ancestral Kejia dialect in favour of Cantonese and PTH in public settings:

Last year was the 150th anniversary of the arrival of the First Hakkas in Suriname. From Huiyang, Dongguan and Baoan, but mostly from Dongguan and Baoan, those first Hakkas came to endure hardship and create their businesses and institutions out of nothing. Those first

8 This hierarchical view of language is reflected in the Chinese-language media in Suriname. Various Surinamese radio and television stations carried a number of Chinese-language broadcasts, notably the daily China Central Television slot on the State Tv broadcaster sTvs. In July 2005, a Chinese-language radio station (Viva-953 on FM radio, of the Suriname Chinese Media Groups Foundation/蘇理南華語創作媒體) started broadcasting in Cantonese and PTH (Zhonghua Ribao 中華日報 12 July 2005, 蘇理南中文電台, FM 匯聚 953 頻道致 蘇理南僑胞的公開信 (Open letter to the Chinese of Suriname from Chinese-language radio on 953 FM); XNRB 4 July 2005, announcement by 'Suriname Chinese Media Groups Foundation'). In February 2008, a Chinese TV station (sCTS on channel 45, of Stichting Kong Ngie Tong Sang TV) which re-broadcasts programmes from the PRC in PTH, was opened in Paramaribo This TV channel basically developed out of the sTvs Chinese-language slot. $<$ http://surinaams.caribiana.nl/Cultuur/car20080208_sctv-chinees >. 
Chinese set up Kong Ngie Tong Sang (more than 120 years old), Chung Fa Foei Kon, Fa Tjauw Song Foei, and later also Hua Cu Hui and Chung Tjauw Fu Li Foei.

Kejia is spoken at the monthly general meetings of the associations, and during the RoscA meetings as well. ${ }^{9}$ Why? Because they and their ancestors are Hakkas, so they all speak Kejia. But certain people, even though their ancestors, their parents, they themselves and their descendents are all Hakkas, often do not speak the language they use at home, even rejecting it as though any other random language can raise their status.

During this year's Moon Festival only Minister Jong Tjien Fa [former Minister of Trade and Industry, 2002-2005] uttered one line of something I would not have dared to call Kejia. Besides this, the three masters of ceremony only spoke Cantonese, Mandarin and Dutch, but not a syllable of Kejia could be heard during that Moon Festival which was organised by Hakkas for all Chinese in Suriname. Someone remarked that this indicated assimilation. I said it was self-alienation, that your own self is authentic. This is so sad!

You must have surely seen how Zhejiangese and Fujianese address people from their hometowns in their own dialect. But only we Hakkas like to speak another dialect, especially Cantonese. If you or your children cannot or will not speak your own language, is that not foolishly suppressing your own roots, is that not aiding in the extinction of Kejia? I would hereby like to press upon you, you who work in education and in society, that it is time to take this issue seriously!

(Zhonghua Ribao 中華日報, 2 October 2004: “客家話正在悄悄地 消亡' (Kejia is quietly going extinct))

Language is the most important issue between the smaller, but more visible and deceptively concrete domain of the China-born (Tong'ap), and the much larger, but diffuse Laiap sphere. All Old Chinese have at least a basic command of the lingua franca variety of Sranantongo, but few Tong'ap are proficient in Dutch, the formal language of the Surinamese State. Laiap seldom speak other Chinese varieties than the local, Surinamese variety of Kejia. Migrants from the Fuitungon region who arrived in the 1980s and 1990s are also fluent in Cantonese and Р $\mathrm{TH}$, but very seldom in any Western language. In short, immigrants are generally illiterate in Western languages, and Laiap are virtually all

9 ROSCA: rotating savings and credit association. The traditional Fuitungon Hakka RosCA is called fui ${ }^{3} t s^{\prime} e n^{2}$ 會錢. 
illiterate in Chinese. So the Tong'ap and Laiap worlds do not meet on Chinese terms, but Laiap have become gatekeepers for Tong'ap vis-à-vis the Surinamese State.

Fuitungon Kejia does not define the distinction between Old and New Chinese, as it is not the only Kejia variety spoken in Suriname since Taiwanese and PRC immigrants have introduced different varieties of Kejia. From the 1980s, people from Chixi in Guangdong Province have established a chain migration network (see below under 'Southerners'); they do not imagine 'Hakka-ness' as defined by and limited to the geographical territory of China. ${ }^{10}$ Asked if Chixi Kejia and Fuitungon Kejia are mutually intelligible, one Chixi Hakka informant in her early thirties answered: "Of course. They're completely the same. We're all Hakkas, we all speak Kejia." This contrasts with the response of a Kejia-speaking Laiap woman of about the same age: "Yes, I can understand them. But it's different. The tones are different. They are Hakkas, but they're not like us." Chixi Hakka children, whether born or raised in Suriname, are fully integrated in Paramaribo society from a young age and are for all intents and purposes Laiap. They speak any combination of Kejia, Yue, Mandarin, Dutch, Sranantongo, and English, unlike their parents, who generally only speak Chixi Kejia and РTH.

Of the 11 Chinese dialect groups, five, namely Northern Chinese ('Mandarin'), Wu, Min, Yue, and Kejia, are now spoken in Suriname by substantial numbers of people mainly from the PRC Provinces of Heilongjiang, Jilin, Liaoning, Shandong, Zhejiang, Fujian, and Guangdong. Chinese dialects are considered markers of regional identity in Chinese cultural contexts, and among New Chinese immigrants in Suriname, this simplistic two-way conflation of language and identity does work to locate various immigrant cohort 'communities' in the ethnic landscape, for the time being at least. For instance, speakers of Wu varieties from Wencheng, Lishui, and Wenzhou can be reasonably sure that they share similar networking loyalties and socio-economic adaptive strategies in Suriname, and that their languages are effective barriers to outsiders.

One can safely assume that all New Chinese migrants are native speakers of some variety of Chinese, and as PRC citizens they also all have learned PTH in school. In the Surinamese context one could describe PTH as the latest

10 Chixi Kejia is unclassified in the Language Atlas of China. Dongguan Kejia may be classified as: Sinitic $>$ Kejia $>$ Yuetai $>$ Xinhui $>$ Dongguan Kejia ( $>$ Laiap Kejia). 
incarnation of the Mandarin koine that prescribed the position of Overseas Chinese with regard to the Chinese polity and the concept of shared Chinese identity. Early Fuitungon Hakka migrants brought with them attitudes towards Mandarin, Cantonese and Kejia that reflect the low status of Kejia. Mandarin is still called $t \sin ^{1} n g i^{1} / t \sin ^{5} n g i^{1}$ (真語/正語 lit.: 'true language'/'proper language'), and Cantonese was called $p^{\prime} a k^{8} w a^{3}$ (白話, lit.: 'white language', meaning 'vernacular'). During the 1930 s and 1940s, the resinicisation project aimed at rallying Overseas Chinese support for the Republican Chinese cause was also implemented in Suriname (Tjon Sie Fat 2009a). The newest Mandarin standard, Guoyu, was taught as the national language of a modern Chinese state rather than as the bureaucratic language that distanced Hakka villagers in China from representatives of imperial power. PTH replaced Guoyu in Suriname only with the arrival of substantial numbers of speakers in the 199os, and the 'resinicisation' drive of the PRC embassy in Paramaribo, which promotes PTH as the universal language of all ethnic Chinese.

However, PTH does not reliably function as an ethnic marker from a Chinese point of view. It is a national and international lingua franca that transcends the various internal ethnic and class boundaries that abound in Chinese cultural contexts. The PRC authorities are also promoting PTH in the belief of a magisterial progression from tool for national unification, marker of globalised Chinese cultural identity and loyalty, to important world language. In Suriname it is not reliable as a conversational barrier, though the number of non-Chinese who can understand Рт H is small. To non-Chinese in Suriname, PTH is indisputably 'Chinese', which places anyone able to speak it squarely in a 'Chinese' camp. In fact, the main linguistic impact of New Chinese within the Chinese language community in Suriname is the increasing importance of Ртн as an intra-ethnic lingua franca. Not only is РTH a prestige language that signals globalised Chinese identity, but it is also a symbol of the growing power of the PRC and thus ethnic pride through PRC patriotism.

The position of New Chinese in the broader context of Surinamese society is also reflected in the languages they do not speak. Immigrants in Suriname can get away with not speaking Dutch, on the condition that they learn Sranantongo, which, even though it is not a prestige language and some Surinamese tend to treat it with even near disrespect, is the medium of informal communication and thus signals the lowering of barriers. In 2003 a common criticism levelled at Chinese immigrants was that they did not speak Sranantongo-which was hardly surprising, as many were fairly recent immigrants who had not yet learnt basic Sranantongo. The charge of arrogance probably involved the common perception that all Chinese speak Sranantongo, but even so Chinese immigrants (who were seen as profiteers) were singled out as problematic. The 
increased discomfort with Chinese immigrants was often expressed by oblique statements, such as, "They should learn the language".11

\subsection{The Northerners}

By the early 200os the largest group of native speakers of Northern Chinese in Suriname consisted of about 100 Shandongese, a slight majority of whom came from Qingdao. Although there might have been individual Shandongese immigrants in Suriname in the early 1990s, there has only been a sustained presence of Shandongese in Suriname since the middle of that decade. Economically, the Shandongese in Suriname were a heterogeneous group, ranging from street vendors to importers. Shandongese and other Northerners are well aware of the prestige they have in Suriname among the Hakkas and other Southerners and Easterners as native speakers of Northern Chinese varieties which are quite close to PTH. Most other native speakers of Mandarin varieties in Suriname are from the Dongbei region (Manchuria). Their presence is the result of PRC technical cooperation projects and resource extraction projects. During the 199os, a group of about 50 construction workers from Nanjing worked in Paramaribo under temporary contracts; a smaller number entered a decade later and set up a construction company catering to ethnic Chinese clients. About $5^{0}$ people from the Dongbei region work in Suriname in logging and construction, as workers and administrators. People working in the timber industry are virtually all from Jilin Province. The China Dalian International Cooperation (group) Holdings Ltd., based in Dalian in Liaoning Province, which started out an extensive road rehabilitation project in Paramaribo during the 199os and early 200os, used construction workers from Nanjing and higher level expatriate staff from Liaoning Province. Dongbei people not involved in logging or construction work in supermarkets owned by Chinese from other backgrounds, and a few individuals own their own businesses.

\subsection{The South-Easterners}

In Suriname, the unflattering Kejia term for New Chinese migrants during the 1990s and early 200os, tset $^{7}$ kong $^{1}$ tsai $^{3}$ (浙江仔, 'those people from Zhejiang Province') reflects the fact that the largest New Chinese group is from the southern part of Zhejiang Province. The majority—possibly more than half of

11 The formula was even repeated by the then President Ronald Venetiaan in a speech during the celebration of the Chinese Lunar New Year on February 1, 2003 in a socio-cultural organisation in Paramaribo, when - speaking Sranantongo at the advice of his hosts - he urged new Chinese immigrants in Suriname to 'learn the language as quickly as possible'. In that particular context, the implied language was Sranantongo. 


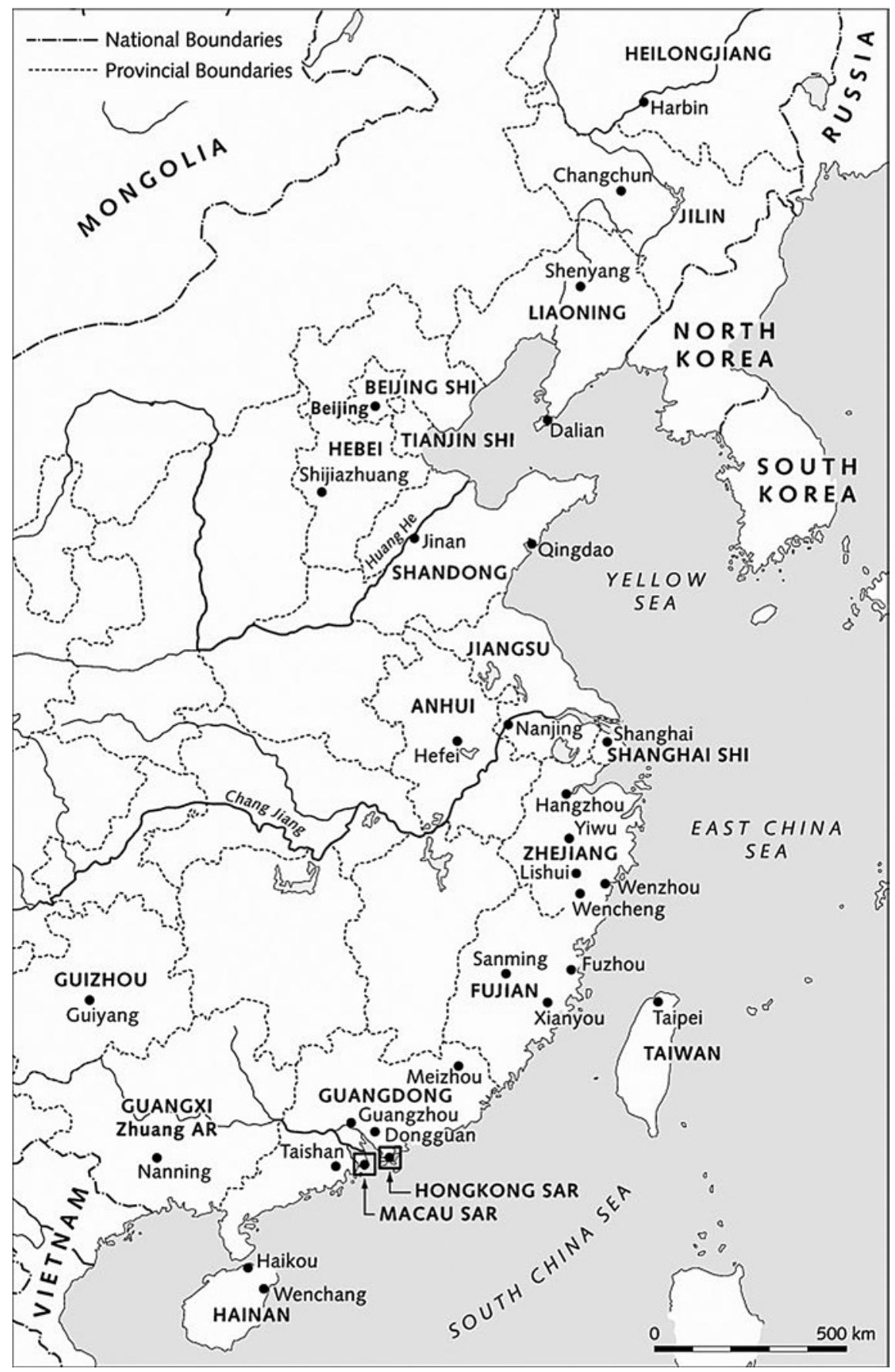

FIGURE 9.1 Hometowns of Chinese migrants in Suriname. 
an estimated 1,000-2,00o people ${ }^{12}$ - are from Wencheng County in Wenzhou, with smaller numbers from Lishui. The Wenzhounese are speakers of varieties of Wenzhounese, ${ }^{13}$ along with different sub-varieties from what is spoken in the Wencheng area, such as Daxue, Rui'an, and Huangdan.

Wenzhounese migrants seem to have found Suriname in the 199os as a natural extension of their European networks, possibly by using the migrant networks of the Fuitungon Hakkas. Zhejiangese entrepreneurial chain migration is basically a variation of the Old Chinese system, with ethnic entrepreneurs sponsoring coregionalists or relatives to come to work in their businesses in Suriname. As a result, most Zhejiangese in Suriname are self-employed owners of supermarkets and 'wholesale enterprises'. The Wenzhounese system is closely tied in with the rapid development of Zhejiangese exports, and it is common among New Chinese, particularly Wenzhounese, in many parts of the developing world. However, Zhejiangese migrants tend to copy local, tried and proven Old Chinese positioning strategies in Suriname, such as socio-cultural organisations, ROsCAs and political patronage (Tjon Sie Fat 2009a). Their particular version of entrepreneurial chain migration has strongly influenced the economic landscape of Suriname.

There were apparently no Fujianese in Suriname before the early 1990s. ${ }^{14}$ Current numbers are impossible to estimate; a few hundred to over a thousand. Although the Fujianese migrants seem to be encouraging the mystery surrounding their presence in Suriname, they publicly-in the local Chineselanguage media-refer to themselves as Fujianese (福建人) and have now organised themselves accordingly (e.g. the 'Fujianese Hometown Association' 福建同鄉會 in Paramaribo). Other than the indisputable fact that there are New Chinese from Fujian Province in Suriname, very little can be said about them. Most Fujianese are said to run supermarkets, but a small group of successful entrepreneurs have reached out into other areas such as logging and mining.

12 There are no formal data on the sizes of the populations of the various regional groups, from either the government or the Chinese organisations. New Chinese and Fuitungon Hakka informants hazarded guesses at my request, and tended to agree on the relative sizes of the groups. In any case, the numbers are estimates, are in no way accurate, and might even be conservative given what is known about the numbers of Chinese citizens entering Suriname (see the Tables and Figure 9.3).

13 Sinitic $>$ Wu $>$ Oujiang $>$ Wenzhou.

14 Strictly speaking, the few Peranakan Chinese in Suriname from Indonesia (all of whom have since remigrated to the USA or Europe) could be said to have had a Fujianese background. 
Linguistic identification is difficult, as many Min varieties are mutually unintelligible and Fujianese therefore tend to use Ртн as a lingua franca. We do know that all major dialect groups are present in Suriname: Minnan, Minzhong and Minbei. In 1991 a Shanghainese informant spoke of migrants from the Jinjiang Area in Fujian Province. In 2002 a Hainanese informant was certain that Fujianese made up the vast majority of New Chinese immigrants in Suriname and that most of these Fujianese were from Sanming in Fujian Province. Minzhong-speaking migrants from a few villages in Xianyou County formed a remarkable subgroup..$^{15}$ Has there been a shift from one Fujianese migrant hometown to another over the years, or have there always been smaller numbers of people or even individuals from other areas in Fujian?

Taiwanese, who are geographically and linguistically linked to Fujian Province, are present in Suriname in small numbers. ${ }^{16}$ Taiwanese in Suriname are like New Chinese in the sense that they are not Fuitungon Hakkas, but their presence has nothing to do with renewed migration from the PRC in the late 1970s. The Taiwanese presence in Suriname can be traced back to the founding of the Surinamese branch of the Kuomintang in Paramaribo (1943), in line with the policy of the Chinese Nationalist government to increase its influence among Overseas Chinese. The Kuomintang government in Taiwan funded a printing press for a Chinese language newspaper in Suriname, Lam Foeng (南風 'Southern Wind') (Man A Hing 1988). Taiwanese taught Mandarin in the Chinese school on the premises of the Kuomintang club/Fa Tjauw Song Foei. But by the time the People's Republic of China was the first foreign state to recognise the newly independent Suriname in 1975, the role of the Kuomintang was over.

In 2003 there were five Taiwanese families in Suriname, with a total of about 20 persons. One family had been there for more than twenty years, fully integrated into Surinamese society, with children who were indistinguishable from Laiap. The four other families arrived in Suriname around 1997, as missionaries of a Taiwanese syncretist 'Daoist' lay group that is active among non-Chinese

15 The group would be called Henghua (Ртн: Xinghua, the name of the older administrative entity that included the current counties of Xianyou and Putian in central Fujian) in Singapore. Henghua migrants are common in Southeast Asia, but comparatively rare in the New World (Fujian Sheng Zhi: 183-188). Associations on the basis of Henghua identity are even rarer there. Xianyou County is not a major migrant sending area. According to the Xianyou Xian Zhi, 7,914 people of a population of 914,756 in 1992 were migrants, mostly entrepreneurial migrants.

16 The island of Taiwan lies across the Taiwan Straits from Fujian Province. The majority of Taiwanese speak Southern Min (Minnan), which is also spoken in southern Fujian, around Xiamen. 
in Latin America and the Caribbean. All speak Guoyu (the national standard of Taiwan), Minnan, and at least one individual spoke Hailu Kejia. ${ }^{17}$

\subsection{The Southerners}

Guangdong Province has obviously provided the vast majority of Chinese migrants to Suriname - the Fuitungon Hakkas. Non-Fuitungon New Chinese from Guangdong, however, are a minority. Apparently, most come from Guangzhou City (Canton) and Taishan (Toisan) in the Siyi Region. ${ }^{18}$ The majority of native speakers of Yue varieties would seem to be from Guangzhou; in fact, numbers of Guangzhou migrants seem to have been substantial enough to warrant the foundation of a 'Guangzhou Hometown Association' (廣州同 鄉會) at some moment before 2007. ${ }^{19}$ Varieties of Yue spoken in Suriname include Hoisan, Standard Cantonese (Guangzhou), Hong Kong Cantonese, Guangxi Yue. ${ }^{20}$

Hainanese migrants form the next prominent group among the New Chinese from the South, with one estimate of about 500 Hainanese (or 100 families) in 2003. Most are from Wenchang, in the North-east of Hainan Province, with smaller numbers from the provincial capital Haikou. The first Hainanese in Suriname apparently arrived as partners of Fuitungon Hakkas, sometime in the late 1980s. Hainanese copied the local Fuitungon Hakka strategy of corner shops and supermarkets, as well as riding the rollercoaster of Zhejiangese commodity export. The dominant language of Hainanese in Suriname is Hainanese, also known as 'Wenchang dialect'. ${ }^{21}$ It is quite different from other Min varieties spoken in Suriname by the Fujianese ${ }^{22}$ and the Taiwanese. ${ }^{23}$

To outsiders, Hainanese in Suriname are not clearly distinguishable from Tong'ap. They copy Fuitungon Hakka attitudes to local positioning, and are Chinese migrants in a very broad sense, with very little 'traditional culture' for non-Chinese to observe. Although Hainan Province is home to four offi-

17 This brings the number of reported Kejia varieties in Suriname to four: Dongguan, Chixi, Meixian and Hailu.

18 Siyi 四邑, 'four counties', refers to the former counties of Taishan, Enping, Kaiping and Xinhui in the west of the Pearl River Delta.

19 The Guangzhou Hometown Association is mentioned first in the Dutch-language Times of Suriname, 28 April 2007, 'Communique "Fa Tjauw Tjoen Foe".

20 Sinitic $>$ Yue $>$ Siyi $>$ Taishan; Sinitic $>$ Yue $>$ Guangfu $>$ Standard Cantonese, Dongguan Yue, Guangxi Yue.

21 Sinitic $>$ Min $>$ Qiongwen $>$ Wenchang.

22 Sinitic $>$ Min $>$ Puxian $>$ Xianyou.

23 Sinitic $>$ Min $>$ Minnan $>$ Taiwanese. 
cial nationalities and at least eight languages in four distinct language groups, ${ }^{24}$ all Hainanese in Suriname call themselves Han Chinese. The more robustly assertive Wenzhounese are much easier for Fuitungon Hakkas to identify and dislike than the Hainanese. Hainanese have one stable organisation in Suriname, the Hainan Hometown Association (海南同鄉會).

Though they are minority among the Southerners, the Chixi Hakkas mentioned earlier are remarkable because they have developed a separate ethnic economy based on urban agriculture in Paramaribo, copied from their hometown. They are chain migrants, sponsoring relatives to come to Suriname to escape the poverty of Xiangling village and provide a better future for their children, who are assimilating into Surinamese society. ${ }^{25}$

Written Chinese (中文) is a potent marker of Chinese ethnic identity. In Chinese cultural contexts Chinese literacy is treated like the hallmark of universal Chineseness, the result of at least a basic education in Chinese script, Mandarin, Chinese literature and history. ${ }^{26}$ The extent of Chinese literacy in Suriname remains unclear, with subscriptions to local Chinese-language newspapers the only publicly accessible data, though numbers of subscribers do not say much about literacy levels among the various subgroups according to assimilation, regional background, educational background, etc. In any case, written Chinese is very much alive in Suriname, from the ability to make

24 The four officially recognised ethnic groups of Hainan are Han (i.e. ethnic Chinese), and the three minority nationalities of Li, Yao, and Hui. These speak, respectively, Sinitic (Wenchang, Haikou and Yue), Tai-Kadai (Lingao, Hlai, Jiamao, Cun), Hmong-Mien (Kim Mun) and Austronesian (Tsat) languages.

25 There are about 200 Chixi Hakkas in Suriname, as well as about 300 Hoisan-speakers from other Taishan districts. Although Hoisan (or Taishanese: Sinitic > Yue > Yue Hai $>$ Siyi > Taishan), is related to standard Cantonese, the two languages are not mutually intelligible.

26 Chinese in Suriname are typically diglossic in the sense that the spoken varieties may be syntactically radically different from the written language. Hakka children spoke a southern language, but learned to write in what was very much a northern variety; written Kejia did not exist to them. However, modern written Chinese is virtually identical to the standard language of the PRC, Putonghua, and though diglossia still applies to the relationship between the non-Mandarin varieties and the written language, the current situation in which people need to learn what is basically the written form of Putonghua and read aloud in the sounds of that language, more closely resembles bilingualism. 
simple lists to poetry submitted to the Chinese-language newspapers. Written Chinese is also a very effective ethnic barrier in Suriname, separating an ethnic in-group from a larger out-group of people who are either not Chinese or 'not Chinese enough. ${ }^{27}$

The Chinese school in Paramaribo is the main generator of local Chineselanguage literacy. The tradition of Chinese schools in Suriname started with reading and writing classes for children of Chinese immigrants (jiàotónghui 教童會: 'association for the instruction of youths') organised by sociocultural organisations. Around the Second World War the Kuomintang promoted 'resinicisation' of Overseas Chinese in Suriname through a Chinese school facilitated by the Fa Tjauw Song Foei socio-cultural organisation. Republican Chinese curricula were intended to 'reconnect' migrant loyalties to the Motherland and Overseas Chinese communities elsewhere in the world. The limited size of the Chinese group meant limited funding and interest in the effects of this Kuomintang resinicisation programme, and eventually the Fa Tjauw Song Foei school faded into oblivion.

The current Chinese school (Zhōngwén Xuéxiào 中文學校, in the Kong Ngie Tong Memorial Building 廣義堂記念樓; in Paramaribo) is run in a more professional manner. ${ }^{28}$ It functions as an expatriate school providing primary education, accredited by the PRC (with plans to extend the programme to secondary education and further). It is a language centre providing courses in Pтн and written Chinese (the school is attended by New Chinese, Tong'ap and Laiap children, and even small numbers of non-Chinese students), as well as continuing the tradition of the jiàotónghui reading and writing classes for Fuitungon Hakka children. (Re)sinicisation is less clearly an ideological goal of this school, as its focus on the PRC is basically pragmatic; the rising power of the PRC means that its language is a valuable asset. However, the curriculum stresses the PTH standard of the PRC as a unifying symbol of global Chinese identity, and spreads the PRC's view of its history and multiculturalism. One consequence is that the school has transcended token literacy in Chinese

27 It is also a growing commercial opportunity. By early 2012 ('Old Chinese' Kejia) individuals involved in language services for the Chinese organisations set up Oriental Media for translation work (Dutch and Sranantongo into written Chinese, Putonghua, Cantonese and Kejia) and video productions for the Chinese-language newspapers and local sCTV broadcaster. (De Ware Tijd daily, 5 March 2012, 'Oriëntal Media slaat brug tussen Chinees en Nederlands').

28 Its ties to the Fuitungon Hakka socio-cultural organisations are not particularly clear-cut. In practice it is jointly run by Kong Ngie Tong Sang, Chung Fa Foei Kon and Fa Tjauw Song Foei. 
script, to promote written as well as spoken PTH in all contexts of Chinese life in Suriname.

A memorandum of understanding on the installation of a Confucius Institute on the grounds of the Anton de Kom (ADEK) University of Suriname in 2011, was signed by outgoing Chairman of the Board of the University Alan Li Fo Sjoe and P RC Ambassador Yuan Nansheng in August 2010. ${ }^{29}$ The Institute is now operational. The global network of Confucius Institutes (孔子學院) was started in November 2004 by the PRC government as a means to extend its soft power across the globe, and in this sense Confucius Institutes are like other institutions for 'international cultural diplomacy', such as the French Alliance Française, and the German Goethe-Institute (Ostler 2010: 245). However, the goal of Confucius Institutes extends beyond mere promotion of Chinese language and culture abroad, into 'mainstreaming' local opinions at the highest levels in accordance with PRC viewpoints on many issues, such as the unity of China (Tibet, Taiwan and Turkestan), the role of Chinese overseas, the PRC as leader of the Developing World, etc. Though ADE K University initially misunderstood it to be a 'sinological institute' funded by Zhejiang Normal University (浙江師範大學), all sides agreed that PTH language courses are the main justification for accommodating a Confucius Institute.

Chinese texts exhibit traces of language change in Suriname, though very little in the form of letters, poetry, diaries, etc. older than thirty years or so survives. Hence, Chinese-language newspapers are the main source. Initially renditions of Surinamese terms were produced in traditional orthography (i.e. predominantly columns of unabbreviated characters read right to left) and reflected the Kejia background of the authors. Some local names have full written Chinese equivalents, without reference to the sounds of the original names. $^{30}$

1. Meerzorg (town across the Suriname River from Paramaribo) Chinese transliteration: 對面海 (“opposite sea”, i.e. “across the water”) Kejia pronunciation: tui ${ }^{1} \mathrm{men}^{5} \mathrm{hoi}^{3}$ PTH pronunciation: duì miàn hăi

\footnotetext{
29 De Ware Tijd 18 August 2010, 'Confucius Instituut in aantocht; mondje Mandarijn vrijwel "noodzaak"'.

30 In the following examples the Kejia transcription uses superscript numbers that link the 6 tones of Kejia to the 8 tonal categories of Middle Chinese: 1, 2, 3, 5, 7, 8. PTH pronunciations are in the official pinyin orthography which uses diacritical marks for the four tones of PTH: ${ }^{-}{ }^{\prime}$, corresponding roughly to Middle Chinese categories $1,2,3^{+4}, 5^{+6}$ (7 and 8 are realised as any of the four tones).
} 
2. Henck Aaronstraat (street in downtown Paramaribo)

Chinese transliteration: 銀行街 (“bank street”, referring to the head office of De Surinaamsche Bank)

Kejia pronunciation: nyun $^{2}$ hong $^{2} \mathrm{kai}^{1}$

PTH pronunciation: yín háng jiē

The influx of 'Hong Kong Chinese' in the 196os led to an increase in Cantonese dialect influence. Currently, written Chinese in Suriname is in line with PRC standards, which means that the mixed orthography of horizontal lines and vertical columns has given way to a more unambiguously PRC standard of horizontal lines of abbreviated characters reading left to right. This also means that Surinamese terms are transliterated based on PTH readings. The following are examples of older Kejia-based transliterations of local names:

3. Parbo Biri (Sranantongo, "Parbo Beer")

Chinese transliteration: 巴波啤利

Kejia pronunciation: $p a^{1} p o^{1} p i^{1} l i^{3}$

PTH pronunciation: $b \bar{a} b \bar{o}$ píli.

Current standard: 巴波啤酒, РTH pronunciation: $b \bar{a} b \bar{o}$ píjiǔ, lit.: “Parbo beer"

4. Albina (border town on the Marowijne River)

Chinese transliteration: 阿明那

Kejia pronunciation: $a^{1} \min ^{2} l a^{3}\left(>n a^{3}\right)$

PTH pronunciation: $\bar{a}$ míng nà

5. Nickerie (border town on the Corantijn River)

Surinamese Dutch and Sranantongo pronunciation: [ni'keri]

Chinese transliteration: 日計里

Kejia pronunciation: git $^{7}$ (>nyik $\left.{ }^{7}\right) \mathrm{ke}^{5} \mathrm{li}^{1}$

PTH pronunciation: rìji lǐ

6. Zanderij (location of the J.A. Pengel International Airport)

Surinamese Dutch pronunciation: [zandə'rei]

Chinese transliteration:山低乃

Kejia pronunciation: $\operatorname{san}^{1}$ tai $^{1}$ lai $^{1}$

PTH pronunciation: shān dī nǎi

7. Wanica (district name)

Chinese transliteration: 完里加 


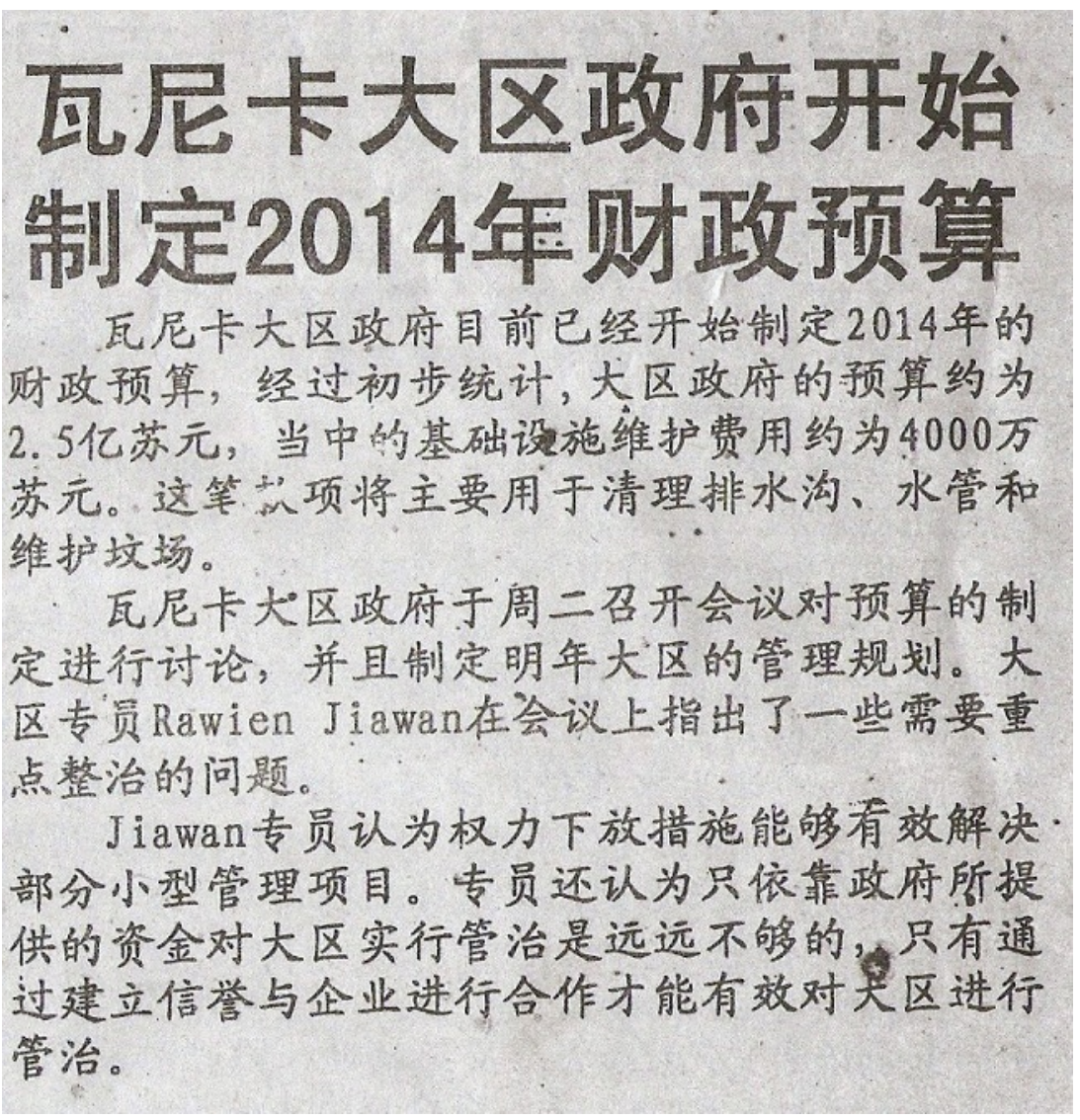

FIGURE 9.2 Article in Chung Fa Daily, 30 May 2013, "Wanica District Government starts formulating 2014 budget".

Kejia pronunciation: wan $^{2} l i^{1}\left(>n y i^{1}\right) k a^{1}$ PTH pronunciation: wán líjiä

Alternative Chinese transliteration: 完宜加

Kejia pronunciation: $w_{a n}^{2} n g i^{2}\left(n y i^{2}\right) k a^{1}$

PTH pronunciation: wán yíjiā

Alternative Chinese transliteration: 完尼加

Kejia pronunciation: wan $^{2} l i^{2}\left(>n i^{2}\right) k a^{1}$

PTH pronunciation: wán níjiā

Most of these transliterations are considered established written Chinese in Suriname. All newer transliterations are based on PTH pronunciations, as in the example in Figure 9.2, were Wanica is transliterated as 瓦尼卡 and read 
as wă ní kă. Here too there is no real standardisation in practice, and different transcriptions of the same names can occur in the same newspaper alongside untranscribed names in Latin script. Examples are names of prominent Surinamese individuals and place names:

8. Venetiaan (Ronald Venetiaan, former Surinamese president) Surinamese Dutch: [fənei'fa:n]/[fənei'fan], deliberate pronunciation: ['feineitsia:n]

Chinese transliteration: 菲里西安 ${ }^{31}$

Kejia pronunciation: $f u i^{1} l^{1}\left(n y i^{1}\right) s i^{1} o n^{1}$

PTH pronunciation: fé̀i lı̌x xì àn

Alternative Chinese transliteration: 費内西恩 ${ }^{32}$

Kejia pronunciation: $f u i^{5} l u i^{1} \mathrm{si}^{1} \mathrm{en}^{1}$

PTH pronunciation: fèi nèi $x \bar{l} e \bar{n}$

9. Bouterse (Desi Bouterse, current Surinamese president)

Surinamese Dutch: ['boutərsə]

Chinese transliteration: 鮑特斯

Kejia pronunciation: $\mathrm{pau}^{1} \mathrm{t}^{\prime} \mathrm{t}^{8} \mathrm{~s} \mathrm{u}^{1}$

PTH pronunciation: bào tè sĭ [pauy th ${ }^{\mathrm{h}} \gamma \mathrm{y}$ sị]

Alternative Chinese transliteration: 鮑特瑟

Kejia pronunciation: $p^{\prime} a u^{5} t^{\prime} i t^{8}$ sit $^{7}$

PTH pronunciation: bào tè sè [pauy thry sry]

10. Marowijne (district in the north-east)

Surinamese Dutch pronunciation: [maro'wsinə]

Chinese transliteration: 馬羅韋納

Kejia pronunciation: $\mathrm{ma}^{1} \mathrm{lo}^{2}$ wui $^{2} \mathrm{lap}^{8}\left(\mathrm{nap}^{8}\right)$

PTH pronunciation: mă luó wéi nà

31 The use of 里 seems to indicate the influence of Southern Chinese pronunciations, where syllable-initial [n] and [1] are allophones of /n/. A more unambiguously PTH transliteration might have been 菲尼西安 ( féi ní xī ān). Literary pronunciations in Kejia are no longer relevant in Suriname, while colloquial Kejia renditions of local names lack a stable written basis.

32 Once established in the text, transcribed names may be abbreviated to the first character. 'Former president Venetiaan' then becomes 費前總, from 費内西恩前總統 (Venetiaan-earlier-president). 
The shift away from Kejia dialect is also apparent in the decreasing use of local expressions associated with Hakka (chain) migration, such as:

11. Suriname

Written Chinese: 洵南33

Kejia pronunciation: $\operatorname{sun}^{2} \operatorname{lam}^{2}\left(>\operatorname{nam}^{2}\right)$

PTH pronunciation: xún nán

Current international standard orthography: 蘇里南

Kejia pronunciation: $\mathrm{su}^{1} \mathrm{li}^{1} \mathrm{lam}^{2}\left(\mathrm{nam}^{2}\right)$

PTH pronunciation: sū lǐ nán.

12. 來埠 lit.: "Come to the port city (= Paramaribo)", i.e. "(fresh chain migrants) coming to Suriname"

Current standard usage: 來蘇里南 lit.: "Come to Suriname"

\section{The Chinese the Government Doesn't Hear: 'Chinese' in Official Data}

There are many reasons why Chinese languages have gone unexplored in Suriname. The Chinese segment has always been a numerical minority and successful assimilated Chinese were efficient gatekeepers between immigrants and Surinamese society, which meant that no Chinese variety was ever an inter-ethnic contact language. Orientalist stereotypes of Chinese as the ultimate, abject Other also combine with Surinamese multiculturalist discourse to feed the notion that Chinese ethnicity and Chinese language are equivalent, monolithic and obvious; 'Chinese speak Chinese'. Surinamese views of culture are clouded by post-colonial fixations, in particular the multiculturalist discourse that informs Surinamese ethnopolitics, and its patriotic populist nation-state counter-discourse of Surinamese nationalism (cf. França 2004; Tjon Sie Fat 2009a). As a result, there is a rather schizophrenic notion that ethnicity, and thus culture and 'ethnic languages', are potentially divisive but equally emblematic of Surinamese multicultural identity.

33 This transliteration survives in names of old local institutions, such as the Chineselanguage newspaper 洵南日報 ‘The Suriname Daily’ and the Chinese cemetery 洵南華 僑公山 'Overseas Chinese Cemetery of Suriname'. Unlike the current, purely phonetical, standard Mandarin-based transliteration of 'Suriname', 洵南 carries a number of poetic allusions that reflect the experience of chain migration: 'the promise of the south', 'the distant south', 'quiet weeping in the south'. 
Language is a very important marker of ethnic identity in Suriname, where up to the late 1940 s the various languages and language varieties predictably defined ethnicity and class (Eersel 1983). In popular discourse the language situation in Suriname is generally described as a set of nested domains, rather like Russian matryoshka dolls, with oneself at the centre. Languages such as English that enable contact with the region and larger globalised reality dominate the outer shell. The middle spheres contain (Surinamese) Dutch in formal citizenship and (lingua franca) Sranantongo for the informal realm of social interaction. The innermost domains of ethnic community and family life contain the 'ethnic languages' which are first and foremost ethnic markers within the context of Surinamese multiculturalist ideology—apanjaht thinking (França 2004; Tjon Sie Fat 2009a).

Both the multiculturalist and popular multilingual views of language treat local languages as intimately tied to ethnic groups. This informs the way linguistic data is collected by the State. The conundrum Surinamese state institutions find themselves in is how to avoid atomising society while collecting the widest range of relevant data possible. The Algemeen Bureau voor de Statistiek (ABS, General Bureau of Statistics) is the only institution in Suriname that regularly collects ethnic and linguistic data at the national level. Ethnic categories and linguistic categories in ABS publications have gone unchallenged, despite the fact that they are very vague. The ethnic categories are fundamentally racial, reflecting Surinamese multiculturalism, and its underlying Caribbean racial black-white dichotomy. ${ }^{34}$ The linguistic categories also derive from Surinamese multicultural discourse and were not selected from a need for sociolinguistic information.

Sarnami Hindi and Javanese are the only two language labels that are relatively unproblematic; Sarnami Hindi refers to Sarnámi, and Javanese refers to the local variety of Javanese. One could argue that the need to fine-tune the categories of the pluricentric Dutch and English languages is not relevant for the purposes of household surveys, but the fact that the language labels 'Amerindian', 'Bushnegro/Maroon dialects' 35 and 'Chinese' are solidly linked to the ethnic categories of 'Amerindian', 'Maroon' and 'Chinese' only serve

34 The 2009 household survey of the ABs contains a category labeled Blank in Dutch, translated as 'Caucasian'. A footnote to the label states that 'CCaucasian" [was] formerly designated "European". Even clearer, Dutch Creool is rendered as 'Creole (Negro)'. ABs 2009a: 88: Table 13 .

ABS 2009a, p. 88: Table 13. has 'Bushnegro', whereas Table 14 has 'Maroon dialects'. 'Bushnegro' was used as a language label in the 1998 and 2011 ABs Household Survey reports, while 'Maroon' was used in the 2009 publication. 
to reinforce the view of language as an ethnic boundary marker. Indeed, the Amerindian language label does not take into account the fact that seven different languages belonging to two distinct, and mutually unintelligible language families, Cariban and Arawakan, are spoken in Suriname. The same holds for Maroon and Chinese categories, and fine-tuning the Maroon and Chinese language labels might help social planners understand internal and international migration patterns.

Only with the 7th General Census, held in 2004, did the ABs survey second language use. In a strongly multiethnic and multilingual society such as Suriname, language use reflects the importance of cross-cutting social networks. Livelihoods in the highly informal Surinamese economy depend on the ability to foster ethnic loyalty and thus ethnic identity, for which an ethnic language is an important tool, but also on the ability to form alliances across carefully constructed ethnic barriers, which at a minimum implies the common use of a lingua franca. One would not expect Sranantongo, for instance, to be claimed as a mother tongue by informants who are not firmly identifiable or who do not self-identify as Afro-Surinamese, but the importance of the language as a national lingua franca would likely emerge from questions about the most used language outside of the household. As long as the majority of Surinamese view language as a fundamental ethnic boundary marker and believe that ethnicity is essential and inheritable rather than constructed and changeable, it is unlikely that the Surinamese State will be able to reduce its self-imposed deafness to language.

Table 9.1 presents the only public data available on Chinese language in Suriname spanning multiple years in a region where most (self-identified) 'ethnic Chinese' reside, namely the Municipal District of Paramaribo and the periurban District of Wanica. ${ }^{36}$ Consistent, clear-cut Chinese categories do not emerge from the data, which in any case are not highly significant because of discrepancies due to methodology. The data seem to indicate that numbers of Chinese speakers and ethnic Chinese (both undefined) are steadily increasing.

The 2004 Census (ABS 2005, 2006a, 2006b) counted 7,804 ethnic Chinese in the districts of Paramaribo and Wanica, of which the vast majority $(7,151$ or about 92\%) lived in Paramaribo. By comparing the District data numbers with the national census figures one gets an idea of why Chinese demographic data for Paramaribo/Wanica can represent the whole country; $89 \%$ of the 8,775 ethnic Chinese counted in Suriname lived in Paramaribo/Wanica according to the census. At both national and district levels the percentage of PRC

36 Data from household surveys: ABS 1999: 100-102 (Table 13A, Table 13B, Table 14); ABS 2009a: 88-89 (Table 13, Table 14); ABs 2011a: 73-74 (Table 13, Table 14). 
TABLE 9.1 Ethnic Chinese in Paramaribo and Wanica stating their mother tongues

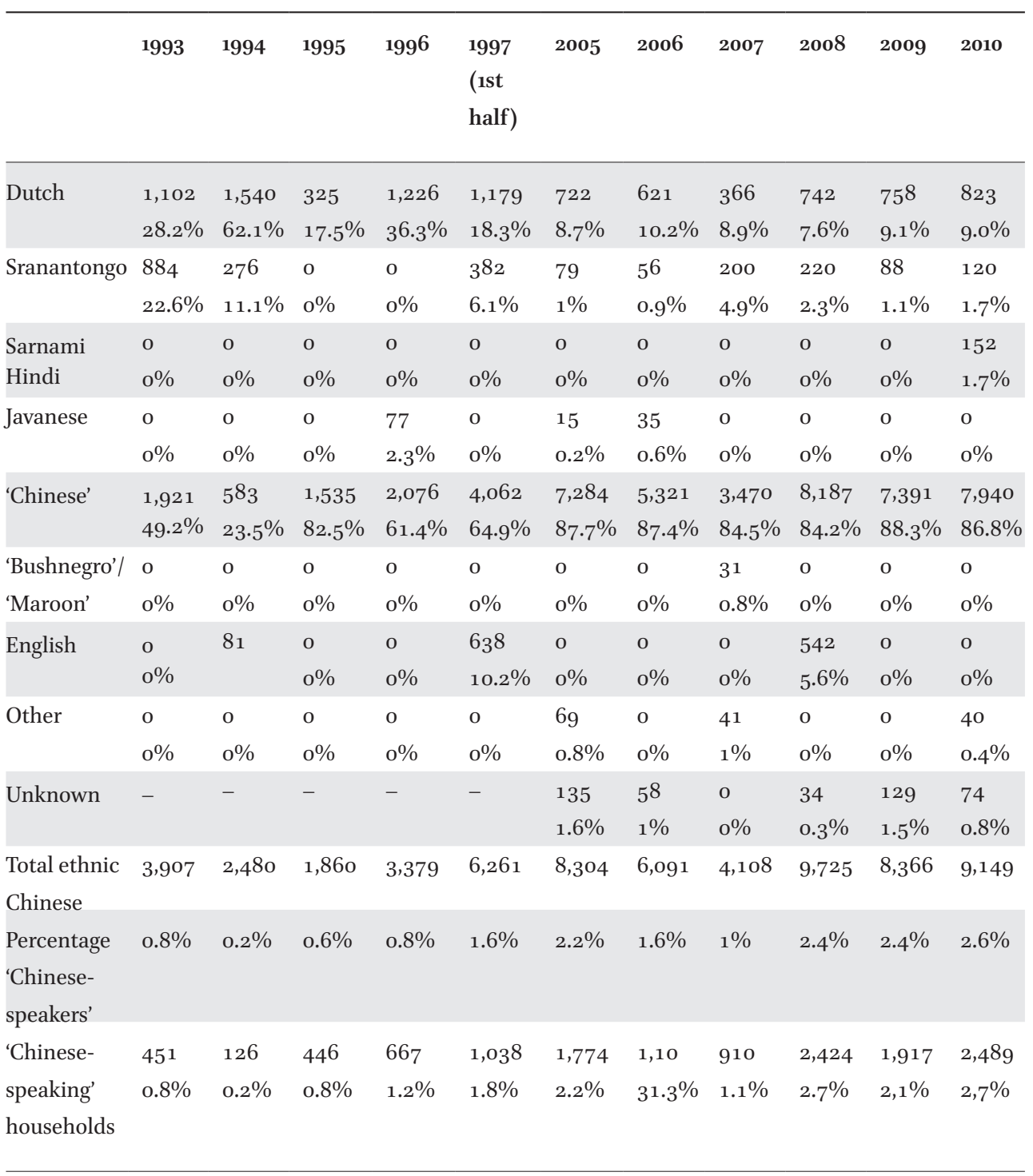

citizens among the ethnic Chinese was about $40 \%$, which says little about actual migrant numbers, only that Chinese immigrants make up a substantial part of the ethnic Chinese segment.

Table 9.2 is an extract of Table 9.1, and shows overlaps between Javanese and Chinese ethnic categories with regard to Chinese as a mother tongue. It might 
TABLE 9.2 Number of Chinese-speakers by ethnic category, Paramaribo and Wanica

\begin{tabular}{lllllllllllll}
\hline & 1993 & 1994 & 1995 & 1996 & 1997 & 2005 & 2006 & 2007 & 2008 & 2009 & 2010 \\
\hline Javanese & 0 & 0 & 0 & 149 & 0 & 0 & 0 & 0 & 0 & 0 & 0 \\
'Chinese' & 1,921 & 583 & 1,535 & 2,076 & 4,062 & 7,284 & 5,321 & 3,470 & 8,187 & 7,391 & 7,940 \\
Caucasian & 0 & 0 & 0 & 0 & 0 & 0 & 0 & 0 & 0 & 0 & 31 \\
Mixed & 0 & 0 & 1,107 & 0 & 0 & 41 & 0 & 0 & 241 & 0 & 10 \\
Unknown & 104 & 0 & 0 & 0 & 0 & 0 & 0 & 0 & 0 & 0 & 0 \\
\hline
\end{tabular}

have been an artefact of methodology, but in 1996 there were suddenly 77 Chinese who spoke Javanese and 149 Javanese who spoke 'Chinese'. In 2005 and 2006 there were respectively 15 and 35 ethnic Chinese who claimed to be mother tongue speakers of Javanese. According to the data, no ethnic Chinese ever claimed to be a mother tongue speaker of Sarnámi or an Amerindian language, but in 2007 there were $3^{1}$ ethnic Chinese who claimed to speak a Maroon language as a mother tongue. ${ }^{37}$

Table 9.3 gives numbers of households (not individuals) with regard to first-language and second-language speakers of 'Chinese' in Paramaribo and Wanica in 2003-4, without reference to ethnic category. ${ }^{38}$

The 'Chinese' ethnic and linguistic categories in ABs publications reveal the problem with the inherently essentialist view of ethnicity in Surinamese multicultural discourse that makes ethnic language an unambiguous marker of ethnic category: what are 'ethnic Chinese', what is 'Chinese language', and what is the relationship between the two? The 'Chinese' language label used by the $\mathrm{ABS}$ is static, and does not take into account the reality of the rapidly changing linguistic situation among local-born and immigrant ethnic Chinese. No distinction is made between varieties of Chinese that could be labelled as indigenous or immigrant languages. Kejia, in particular Laiap Hakka, could rightly be labelled a Surinamese language, but Mandarin is linked to immigrants, like Brazilian Portuguese. Even so, one assumption does hold water; PRC immigrants speak РTH, so get hold of their numbers, and one has the majority of PTH speakers. However, without reliable migration data, nothing is certain.

\footnotetext{
37 Data from: ABS 1999: 100-102 (Table 13A, Table 13B , Table 14); ABS 2009a: 88-89 (Table 13, Table 14).

38 Data from the 2004 census: ABs 2006b, Table 1 'Number of households according to primary spoken and second languages'; ABS 2006c, Table 1 'Number of households according to primary spoken and second languages.'
} 
TABLE 9.3 First and Second Languages in Households: Paramaribo and Wanica, 2004 Census

\begin{tabular}{|c|c|c|c|c|}
\hline & & \multicolumn{3}{|c|}{ 1st language in household } \\
\hline & & Dutch & Sranantongo & 'Chinese' \\
\hline 2nd language & Dutch & $x$ & 4,144 & 200 \\
\hline \multirow[t]{13}{*}{ in household } & Sranantongo & 28,302 & $x$ & 640 \\
\hline & Sarnami & 5,995 & 432 & o \\
\hline & Javanese & 3,938 & 421 & o \\
\hline & Indigenous language & 59 & 46 & o \\
\hline & Maroon language & 1,248 & 595 & o \\
\hline & ‘Chinese’ & 123 & 85 & $x$ \\
\hline & Portuguese & 95 & 25 & 2 \\
\hline & English & $1,35^{\circ}$ & 294 & 22 \\
\hline & French & $5^{2}$ & 42 & o \\
\hline & Other & 209 & 84 & 2 \\
\hline & None & 5,972 & 772 & 294 \\
\hline & Unknown & 149 & 32 & 5 \\
\hline & Total & 47,492 & 6,972 & 1,165 \\
\hline
\end{tabular}

Born of a collection system shaped by ideological preconceptions, it is no surprise that the available data seem to confirm ethnic stereotypes. That does not mean that they are useless. The data on Dutch/Sranantongo versus 'Chinese' do seem to indicate that processes of assimilation are ongoing (see Tables 9.1-9.3), with monolingual Chinese-speakers a minority, and most being bilingual or even trilingual, very likely reflecting the dichotomy between Tong'ap and Laiap among the Hakka. Despite the data gap between 1997 and 2006 in the Household Surveys, numbers of Chinese speakers and ethnic Chinese in the main districts of Paramaribo and Wanica would seem to be steadily increasing, while other ABS data suggest that the trend for Chinese nationals entering Suriname seems to have levelled off since the early 1990s (see Figure 9.3 below). ${ }^{39}$ Many questions remain unanswered. Were Chinese migrants quickly remigrating in the early 199os? Were settlement patterns more stable in the 200os? Which Chinese languages are becoming established, which are dying out?

Data from: ABS 1999; 2005; 2006a; 2006b; 2006c; 2009a; 2009b; 2011a; $2011 b$. 


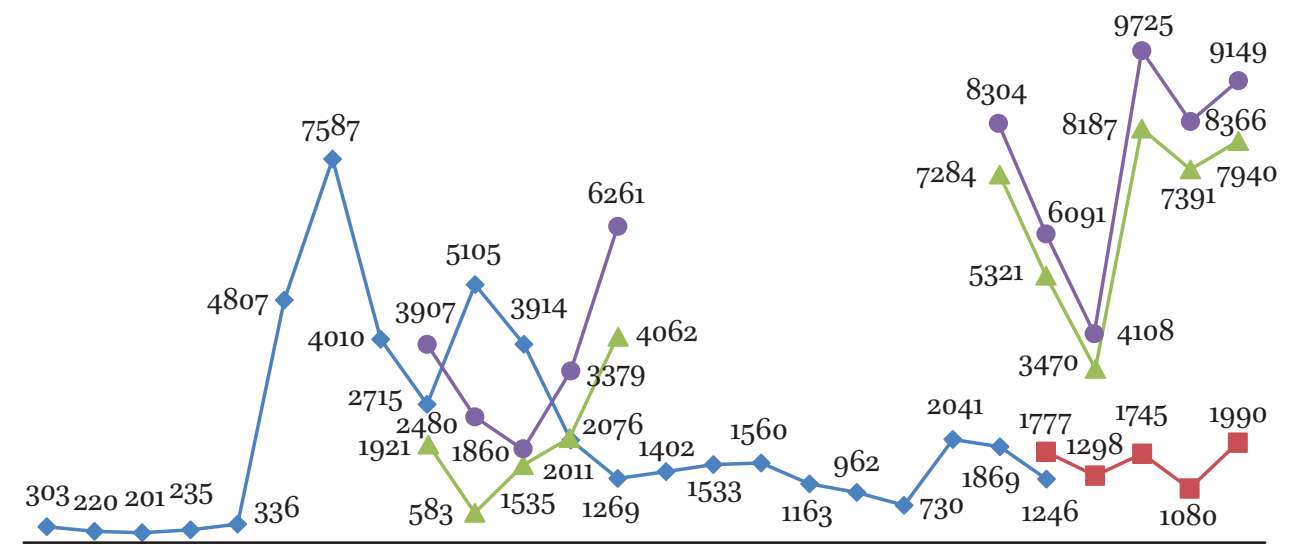

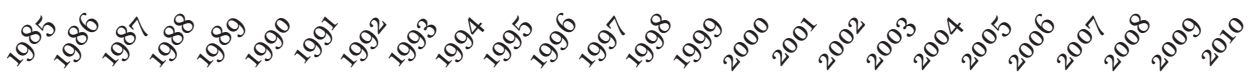

- Numbers of non-resident Chinese nationals entering via the international airport

- Numbers of non-resident Chinese nationals entering via all ports (change in data submitted to ABs)

- Numbers of ethic Chinese according to ABs Household Surveys

$\triangle$ Numbers of 'Chinese speakers' according to ABs Household Surveys

FI GURE 9.3 Numbers of Non-Resident Chinese Nationals Entering Suriname.

Besides on television, Chinese language can be heard by Surinamese in Chinese businesses and anywhere ethnic Chinese and Chinese migrants congregate, usually Chinese restaurants and Chinese community events such as Chongyang, Lunar New Year, and Moon Festival celebrations. The programmes on TV Channel 45 are in PTH, and to a lesser extent in Cantonese and Kejia (particularly in translations of local news reports). Public events are mediated in PTH and regional languages, and in Cantonese when there is a Hakka majority. However, most non-Chinese do not attend Chinese public celebrations, and are outsiders to Chinese-language media. One can safely claim that Surinamese do not hear Chinese, but see Chineseness. Why?

Current social constructionist approaches to social identities refute the notion that personal identities are subcategories of fixed, primordial groups. Instead, ethnic groups for instance- the commonsensical idea that groups of people exist 'out there', which Brubaker (2004) prefers to call 'groupness' - are brought into existence by the performative nature of ethnicity in Suriname, much as what Butler (1990) observes with regard to gender identities; identity is not about fixed categories, but arises in the performance of it by individual 
subjects. In her analysis of gender development, Butler sees performativitytypes of authoritative speech, with the power to frame objects which they are meant to describe - as the way in which identity is passed on or brought to life by discourse.

To Butler, gender is like a script which is made a reality by repeated performance. Gender is therefore an expression, not of what someone is but of one's acts, and as social distinctions such gender, ethnicity, class, and body always intersect, no 'doing' of one identity happens in isolation from any other. In any case, the notion of performative scripts allows us to analyse ethnic 'groups' as events, and to distinguish between groups arising organically or as political projects of organisations which claim to represent ethnic interests (Brubaker 2004: 11-13). At the individual level personal identity is also situational, instrumental, and multiple, and Chinese identity is just one of many self-concepts that individuals derive from perceived membership of social groups, relevant to positive self-esteem. In this psychological sense 'Chineseness' is dynamic, constantly adapting to provide consistency and guidance for the individual's actions, while the 'truth' of one's personal experience is irrelevant.

This is not to say that social identities are expressions of free speech. One can observe that there are limits to the freedom to choose identities. In the case of Chinese in Suriname, there is a gap between the identity one performs (calling oneself Chinese) and the identity one cannot shake off (being called Chinese). Different identities are not equal when race, gender and class are about power relations, so the question as Shimakawa (2004) puts is: does everyone have equal access to agency in choosing positional, multi-situated identities? Writing on 'Asian' identity in the USA, Shimakawa sees the process of Othering: "... the seemingly contradictory, yet functionally essential, position of a constituent element/sign of American multiculturalism and radical other/ foreigner" (Shimakawa 2004: 151). Shimakawa uses Kristeva's concept of abjection to approach us Asian ethnic performativity: a state as well as a process in which things about oneself that are considered objectionable are jettisoned to produce 'perceptual and conceptual borders around the self', '... the condition/position of that which is deemed loathsome and the process by which the subject/"I" is produced' (Kristeva 1982, quoted in Shimakawa 2004:150).

Shimakawa reads Asian Pacific Americanness as an effect of 'national abjection'; the production of national identity through the designation of things deemed un-American. In a similar vein, the prevalent way of thinking about Chineseness in Suriname is based on the defining of Surinamese by national abjection of 'Chinese'. This appears ambivalent because it is based on the binary set of Chinese stereotypes produced by a dominant negative discourse that defines speech about Chinese in terms of contamination and threat, 
accompanied by its positive twin that produces positive images of Chinese. But as a performative act (an illocutionary speech act), the use of the word 'Chinese' in the Surinamese media describes as well as prescribes Chinese as irregular migrants, associated with organised crime, exploiters, pandemics, and more recently, neo-colonisers. The lack of differentiation in the word meant that all Chinese in Suriname were, are, or might be problematic (Tjon Sie Fat 2009a).

Stepping away from performativity, one may also consider how Chinese in Suriname are othered, and Gerd Baumann's conceptual framework for that process is helpful here (Baumann 2004). He identifies three grammars of identity and alterity, grammars in the sense that they provide prescriptive, normative rules for identifying oneself by positioning others: orientalisation, segmentation, and encompassment. Orientalisation, "constitutes self and other by negative mirror imaging: 'what is good in us is lacking in them', but also adds a subordinate reversal: 'what is lacking in us is (still) present in them'. It thus entails a possibility of desire for the other and even, sometimes, a potential for self-critical relativism." (Baumann 2004: $\mathrm{x}$ ). In Suriname, this negative mirror imaging produces a double set of Chinese stereotypes, with the negative stereotypes dominating (Tjon Sie Fat 2009a: 381-383). Here too Chinese emerge as the constitutive other to a vaguely defined 'Surinamese identity'.

The discourse of 'Chineseness' thus makes speaking, reading, and writing 'Chinese' a performative act. Compared to the other canonical ethnic groups in Surinamese multiculturalism, Chinese appear more closely linked to their ethnic language- 'Chinese'. But Sranantongo is strongly associated with ethnic Chinese, as shopkeepers needed to use the (pidginised) lingua franca version to communicate with their clients. "They don't speak the language" reflects the observation that under renewed immigration there are now Chinese shopkeepers who do not speak Sranantongo. ${ }^{40}$ On the one hand, patterns of language acquisition among immigrants have changed, with more people than there are opportunities to learn the ropes of shopkeeping — including learning basic Sranantongo-in existing supermarkets. On the other hand, the basic pattern of Chinese linguistic adaptation still holds; non-Kejia speakers from China are pioneering their own socio-economic niches as though there were no earlier Chinese migrant cohorts, and are slowly creating their own contexts for chain migrants to learn Sranantongo. It should be noted that exclusive use of Sranantongo without Dutch marks class identity. No matter how successful

40 Remarkably, the only people in Suriname who would correct my Sranantongo, which I do not speak fluently, were Chinese migrants (Tong'ap). Anyone else would keep a polite silence, ridicule mistakes, or turn out to be unsure about correct forms. 
Chinese immigrants may become, Sranantongo will limit their acceptance by all Surinamese classes.

Chinese literacy and fluency in any form of spoken Chinese have different effects with regard to performativity. Writing and reading Chinese characters serve to distinguish Chinese from non-Chinese in a way that is understandable far beyond the local context of Suriname. Basic Chinese literacy is probably the most effective Chinese ethnic marker in Suriname, but written Chinese goes further as a way of 'doing' class identity within the 'Chinese language community'. The ability to write fluently, in a calligraphic hand, using the most obscure characters, in a literary style, implies a profound knowledge of classical Chinese culture, the culmination of high-class education. Speaking Chinese is an act of performative class, ethnic and gender identity. It helps racialise the speaker in Surinamese multi-ethnic contexts as a 'Chinese', but the variety of Chinese spoken identifies the regional background of speakers within a Chinese context. Some dialects create sub-ethnic niches in Suriname, such as Wenzhounese, which in Suriname is spoken only by people from the Wenzhou area.

Recent immigrants bring with them prevailing attitudes towards dialect in the PRC, basically that PTH should dominate in public settings, Chinese or otherwise. In short, Chinese sub-ethnic identities are not performed in public. This was the case for Hakka identity for much longer in Suriname, and Kejia still takes second place to Cantonese in public settings; Kejia is still a peasant language, Cantonese signals urban modernity. It is unclear what exactly the relationship is between the other 'dialects' and the high-status PTH medium is in Suriname. In practice it is very difficult to hear any Chinese variety other than Ртн in any public gathering; publicly, Chinese identity is modern, unified, mainland, and Mandarin-speaking. ${ }^{41}$ The link between Chinese and gender is more subtle. In the past, writing Chinese characters was men's work in Suriname, while good (immigrant) mothers taught their children to speak proper Chinese, while now a high-pitched speaking style in PT H adopted from PRC media culture distinguishes female from male presenters at community events.

41 Chinese dialects can be heard via the Surinaamse Chinese Televisie Station [sic]/廣義堂 蘇里南電視臺, the Chinese-language broadcaster on local channel 45. News is broadcast in PTH, Kejia and Cantonese, and TV series are in PTH if from the PRC, Cantonese if from Hong Kong, and Minnan if from Taiwan. 
What do Surinamese know about Chinese language in Suriname? Despite quantitative data, admittedly limited, the State knows basically nothing beyond what popular sentiments provide. Though the notion that Chinese language is varied is absent from State data, many educated Surinamese will know about Kejia and its link to the 'Old Chinese', and be aware of Putonghua/ Mandarin and its link to the New Chinese. But the chance that anyone will be knowledgeable about other varieties of Chinese in Suriname is slim. The idea that Chinese ethnicity is fundamentally a matter of ethnic identity, and that it is obvious, monolithic, and racial infuses all levels of Surinamese society; Chinese language is then simply an ethnic marker in Surinamese multicultural discourse, and requires no further definition.

This view of Chinese language as an ethnic boundary marker is actually based on fact. In Suriname speaking any Chinese language results in an identity statement differentiating between Us and Them, between 'normal' Surinamese versus the ultimate Other, or between 'us Hakka/Wenzhounese/ Northerners/Southerners/Old/New/Tong'ap, etc. versus any ethnic Chinese outgroup, depending on who speaks, who observes, and who the statement is aimed at. ${ }^{42}$ Besides this role as a boundary marker, PTH in Chinese contexts also clearly serves to construct a larger Chinese identity linked to the PRC and modernity, beyond the day-to-day construction of Chinese ethnic identity in multicultural Surinamese society. Then again, it is in the interest of ethnic Chinese stakeholders in Surinamese ethnopolitics to maintain the image of a monolithic ethnic constituency. Ethnic subcategories are not accommodated in local ethnopolitics, if only because they might provide rival political entrepreneurs with a platform for power-sharing negotiations.

One advantage of recording sub-ethnic, regional and/or regional backgrounds would be a better understanding of social developments in Suriname. In the case of Chinese migrants, regional backgrounds are related to migration patterns and economic positioning. For instance, Fujianese migrants are easily linked to illicit or illegal migration or even people trafficking in the international press, but in Suriname this association is not clear. Wenzhounese migrants, very likely the largest group of New Chinese migrants, were instrumental in creating the system of supermarkets selling cheap Chinese commodities as a

42 These performative identities are very much instrumental. One should note that processes of assimilation and integration, with regard to Surinamese society as well as to globalised Chinese identity, mean that in practice Chinese identities in Suriname are converging. 
migrant survival strategy in Suriname (Tjon Sie Fat 2009a). At the moment the development of the transnational network of commodities and Wenzhounese migrants can't be tracked in Suriname. The relationship between Chinese dialects and regionality is such that linguistic data would help quantify regional backgrounds and vice versa. It is a matter of guided analysis of existing data (for instance copies of migrants' passports at the various government institutions) and fine-tuning data collection with regard to language and regional origin (for instance at the ABS).

Mobility has resulted in a mix of Chinese languages that might otherwise not be in contact in the PRC, and has introduced new linguistic hierarchies. Northerners and Southerners use PTH as a lingua franca in Suriname, Old Chinese find that they can no longer ignore PTH, New Chinese find that they ignore Sranantongo at their peril, and all know that Dutch is essential for their children's schooling and social mobility. ${ }^{43} \mathrm{~A}$ local variety of Kejia, often little more than an accent, developed and is dying out in Suriname, heavily influenced by Sranantongo, and strongly linked to local hybrid Chinese identity (Laiap). It is interesting to imagine what other forms of language contact has been going on in the more than twenty years of resurgent Chinese migration to Suriname, and what linguists would uncover in the field, who are knowledgeable with regard to a wide variety of Chinese 'dialects' and are able to negotiate both the Surinamese ethnic landscape as well as understand the shifting performativity of Chinese identity on Chinese terms.

43 The process of integration is right on track among the New Chinese migrant cohorts. In August 2012 I met a university student whom I had gotten to know as a ten-year-old who had arrived with her family from Taishan in Guangdong Province a few years earlier. She was now indistinguishable from the fully assimilated Laiap generation of the Old Chinese. 